\title{
Rede de pesquisa em transportes: um instrumento de transformação e melhora da qualidade de vida
}

\author{
Licinio da Silva Portugal ${ }^{1}$; Josefina Flórez²; \\ Antônio Nélson Rodrigues da Silva ${ }^{3}$
}

\begin{abstract}
Resumo: O artigo apresenta a concepção de uma Rede de Pesquisa em transportes como uma ferramenta para o desenvolvimento de metodologias e diretrizes compatíveis com a realidade das metrópoles latino-americanas que contribuam para promover a integração dos grupos de pesquisa do continente e melhorar as condições de mobilidade e de qualidade de vida de seus habitantes. Apresenta também a estrutura dessa Rede e como, por meio da criação de uma base comum de experiências e práticas bem sucedidas, tem sido realizada a construção e a promoção do conhecimento necessário para se introduzir as transformações desejadas no planejamento integrado dos transportes, em especial dos Pólos Geradores de Viagens (PGVs), na América Latina.
\end{abstract}

Abstract: This paper presents a Transportation Research Network deployed as a tool for the development of methodologies and guidelines tailored to the reality of Latin American metropolises, fostering integration among research groups on this continent with the final aim of improving mobility conditions and upgrading the quality of life of its inhabitants. The paper shows the conceptual structure of this Network and how, through the establishment of a common pool of expertise, it is building up and promoting the knowledge needed to introduce the desired transformations in integrated transportation planning, and particularly regarding Trip Generation Hubs (TGH), in Latin America.

\section{INTRODUÇÃO}

O artigo apresenta a concepção de uma Rede de Pesquisa em transportes como uma ferramenta para o desenvolvimento de metodologias e de diretrizes compatíveis com a realidade das metrópoles latinoamericanas que contribuam para promover a integração dos grupos de pesquisa do continente e melhorar as condições de mobilidade e de qualidade de vida de seus habitantes. A Rede tem como foco a elaboração de modelos e taxas de geração de viagens de empreendimentos, também denominados Pólos Geradores de Viagens (PGVs), o estudo da relação transporte e uso do solo, bem como o desenvolvimento de abordagens para o seu planejamento e localização sintonizados com os interesses sociais e ambientais.

Nesse sentido, inspirado em Portugal e Florez (2006) e a partir de uma revisão bibliográfica ampliada e atualizada, busca-se caracterizar o contexto das metrópoles latino-americanas, seus problemas e especificidades, enfatizando o setor de transportes e o caso brasileiro, pelas informações disponíveis. Ressaltamse a seguir os PGVs e as suas potenciais externalidades nas infraestruturas de transportes e no espaço socioeconômico, bem como as bases para inserir esses

\footnotetext{
${ }^{1}$ Licinio da Silva Portugal, Universidade Federal do Rio de Janeiro, Rio de Janeiro, RJ, Brasil. (e-mail: licinio@pet.coppe.ufrj.br).

${ }^{2}$ Josefina Flórez, Universidad Simón Bolívar, Caracas, Venezuela. (e-mail: josefinaflorez@gmail.com).

${ }^{3}$ Antônio Nélson Rodrigues da Silva, Universidade de São Paulo, Escola de Engenharia de São Carlos, São Carlos, SP, Brasil. (e-mail: anelson@sc.usp.br).
}

Manuscrito recebido em 7/12/2009 e aprovado para publicação em $1 / 3 / 2010$. Este artigo é parte de TRANSPORTES, volume XVIII, número 1, março de 2010. ISSN: 2237-1346 (online). empreendimentos em um projeto de desenvolvimento sustentável. Mostra-se então a formação da Rede como um importante instrumento de agregação e de promoção do conhecimento para implementar as transformações desejadas, além da descrição da sua concepção e organização. Por fim, destaca-se que as mudanças, além de necessárias, são possíveis, até pelas experiências bem sucedidas em transportes já existentes na América Latina, que se caracterizaram pela valorização do conhecimento e da cidadania, como também pela mobilização em torno de projetos de interesse coletivo. A Rede de Pesquisa, ao promover liberdade de criação e autonomia individual na aquisição, geração e distribuição do conhecimento visando a um saber comum, contribui com esse processo.

\section{CONTEXTO DAS METRÓPOLES E DOS TRANSPORTES NA AMÉRICA LATINA}

As cidades, pela sua natureza, normalmente compreendem múltiplas e conflitantes solicitações pelos serviços e infraestruturas sociais, como os de transportes. Tais recursos coletivos, por suas próprias limitações e pelas de ordem política e financeira, não permitem que todas as necessidades sejam atendidas (Prazeres, 1998). Esse processo envolve uma complexidade que se torna mais intensa na medida em que as demandas crescem de forma rápida, concentradas espacialmente e de maneira desordenada, como ocorre tipicamente nas metrópoles latino-americanas (Piccini, 2003).

Depois da Segunda Guerra Mundial, as cidades dos países latino-americanos sofreram processos de urbanização acelerados, em parte como conseqüência das migrações oriundas do campo, atraídas pelo grande 
potencial de desenvolvimento das áreas urbanas. A parcela da população urbana desses países passou em 60 anos (1950 a 2010) de 41,6 para 79,5\% da população total (Vasconcellos, 2000; CEPAL, 2009). Em alguns casos, como no Brasil e na Venezuela, a urbanização foi ainda mais significativa: de 1960 a 2000, a população urbana do primeiro mais que quadruplicou, passando de 32.004.817 para 137.953.959 habitantes (IBGE, 2010) e, no segundo, quase que quintuplicou, passando de 4,7 milhões para 20,2 milhões (Negrón, 2001). Atualmente, vários países, como a Argentina, têm mais de $90 \%$ de sua população urbana. Na América Latina, as taxas anuais de crescimento demográfico, apesar de terem se reduzido, particularmente, na última década, ainda estão, em média, no entorno de 1,15\% (CEPAL, 2009), refletindo um valor superior ao observado nos países desenvolvidos. Cabe destacar que a previsão de crescimento populacional na Inglaterra, para o período de 25 anos (1996 a 2021), foi de 7\% (Prescott, 2005).

Além de rápida e intensa, a urbanização na América Latina ocorreu de forma concentrada no espaço, particularmente em algumas poucas cidades, como indicam os seguintes casos: a cidade do México representa $18 \%$ da população do país, Buenos Aires e Santiago do Chile correspondem a mais de um terço e as onze principais metrópoles brasileiras compreendem 78\% (CEPAL, 2005a; CEPAL, 2009; IBGE, 2010). Já em relação à população mundial urbana, apenas $44 \%$ vivem em cidades com mais de 500.000 habitantes (http://europa.eu.int/comm/europeaid/projects/urbal/in fos/urb11pt.pdf), enquanto na Inglaterra $46 \%$ vivem em cidades com mais de 250.000 habitantes (http://www.odpm.gov.uk), mostrando uma ocupação mais balanceada no território. Neste contexto, observa-se que a América Latina concentra duas das cidades mais populosas do mundo, México e São Paulo, além de outras metrópoles complexas e de difícil administração.

Essa concentração populacional excessiva em algumas localidades talvez expresse as desigualdades de acesso aos meios de transportes e de oportunidades no espaço, que ocorrem nas escalas nacional e regional, mas atualmente com mais visibilidade dentro da metrópole. Nesse ambiente, os grupos mais poderosos e influentes exercem pressão em instituições frágeis e viciadas a fim de canalizar os investimentos públicos, favorecendo seus interesses e reforçando as diferenças sociais e espaciais (Vasconcellos, 2000).

De acordo com a Comissão para América Latina e o Caribe (CEPAL, 2005b; PNUD, 2010), a América Latina e o Caribe conformam a região menos equitativa do mundo. Segundo o Banco Mundial (2003), os 10\% mais ricos da população recebem $48 \%$ da renda total, enquanto os $10 \%$ mais pobres ficam com apenas
1,6\%. Utilizando o índice Gini de desigualdade na distribuição da renda e no consumo, os pesquisadores chegaram à conclusão de que a desigualdade na América Latina e no Caribe, da década de 1970 à de 2000, foi em média 9,9 pontos maior do que na Ásia, 17,5 pontos maior do que nos 30 países da Organização de Cooperação e Desenvolvimento Econômico (OCDE) e 20,4 pontos maior do que no Leste europeu (Banco Mundial, 2003; PNUD, 2010).

Acrescenta-se a isto a escassez de recursos, considerando-se que o fato que mais desequilibrou e empobreceu os países da América Latina nos últimos trinta anos foi o aumento da dívida externa. A dívida era de US\$ 16 bilhões em 1970; US\$ 257 bilhões em 1980 e US\$ 750 bilhões em 2000. Essa última cifra, segundo cálculos da CEPAL e do Sistema Econômico Latinoamericano (SELA, 2003), equivale a 39\% do Produto Geográfico Bruto e a 201\% das exportações da região.

Nesse contexto, a escassez acentua a exclusão dos mais de 200 milhões de pobres (Banco Mundial, 2003; Boye, 2001), produzindo áreas metropolitanas que se caracterizam por apresentar redes de serviços e equipamentos insuficientes e de baixa qualidade; altos índices de violência urbana que afetam significativamente o direito à vida da população; elevada segregação espacial e déficit de moradias, em especial dos segmentos mais pobres, que muitas vezes invadem áreas periféricas sem infraestrutura ou locais mais centrais de acesso restrito (favelas), formando bairros de difícil controle e desconectados do sistema de transportes. No Brasil, por exemplo, de acordo com estudo feito pela Fundação João Pinheiro para o Ministério das Cidades (SNH, 2009), o déficit alcançou o pico de 7,9 milhões de casas em 2006, representando um aumento de 2,5 milhões de residências desde 1991. Apesar da tendência de queda observada no ano subseqüente, o montante é ainda muito expressivo.

A infraestrutura de transportes se insere nesse contexto de desordem, escassez e uso inadequado dos recursos públicos. Os grandes investimentos realizados no setor não têm sido suficientes nem são utilizados de forma equitativa (Habitat, 1987), conforme indicam algumas condições tipicamente observadas nas metrópoles da América Latina (AL):

- A acessibilidade na maior parte do território é ruim e distribuída desigualmente. A configuração da rede de transportes é radial, favorecendo a acessibilidade das regiões mais centrais e valorizadas (Flórez e Portugal, 1996);

- Os núcleos centrais também concentram atividades e empregos, contribuindo para uma dependência das regiões periféricas, cujos moradores precisam vencer distâncias significativas para alcançar seus postos de trabalho. Na América Latina, cerca de 30\% dos empregos se en- 
contram na zona central de negócios (ou CBD, do inglês Central Business District), enquanto nos Estados Unidos da América (EUA) essa proporção é da ordem de 9\% (Kenworthy, 2005). No caso das cidades do Rio de Janeiro e de São Paulo, o tempo de deslocamento médio entre a residência e o emprego, por exemplo, corresponde a uma hora e 24 minutos (PMSP, 2004);

- Os sistemas se baseiam nas modalidades rodoviárias, como os automóveis e os ônibus, apesar das grandes distâncias dos deslocamentos e de corredores com grandes contingentes de viagens (potencializados pelas redes radiais) representarem atributos condizentes com a adoção das tecnologias de transportes de alta capacidade, como os metro-ferroviários. O número anual de embarque per capita em modais metroferroviários na Europa é de 162,2, enquanto na América Latina é de 19,2, quase 9 vezes inferior (Kenworthy, 2005). Nas grandes cidades latino-americanas, é usual se ter mais de $90 \%$ dos deslocamentos motorizados feitos pelos automóveis e ônibus, que se caracterizam por consumirem relativamente mais espaço por passageiro transportado;

- O sistema de transporte público não é hierarquizado e integrado com muitos modais informais e ilegais, estabelecendo uma concorrência predatória entre eles;

- O crescimento acelerado da motorização é outro fator agravante, talvez expressando a alta atratividade despertada pela posse e uso do automóvel (Gakenheimer, 1999). As taxas de motorização no período de 1990 a 1999 cresceram, no Brasil e no México, a 2,7\% e 2,8\% ao ano, respectivamente, cerca de 4 vezes mais que a taxa dos EUA, que foi de 0,7\% (Lopes, 2005). Em 2009, foram mais de 12 mil veículos novos fabricados em média diariamente (http://www.denatran.gov.br/frota.htm). Essa quantidade expressiva de veículos que é acrescentada ao tráfego veicular encontra uma infraestrutura viária de baixa qualidade (Vasconcellos, 2000), com capacidade insuficiente (Gakenheimer, 1999) e não hierarquizada. Enquanto os EUA têm 0,156 metros de vias expressas (freeways) per capita, na América Latina esse parâmetro corresponde a apenas 0,003 (Kenworthy, 2005), ou seja, 50 vezes menos oferta de vias de categoria superior;

- Alta parcela de viagens a pé, não como um sinal de mobilidade sustentável, mas muitas vezes como forma de exclusão, ao se realizarem fora de padrões esperados. Além disso, a infraestru- tura para os pedestres é normalmente precária e deficiente, particularmente nos bairros mais pobres. No Brasil, a população de baixa renda realiza cerca de $60 \%$ de seus deslocamentos a pé (Gomide, 2003), enquanto em CaracasVenezuela, essa modalidade representa 24\% das viagens dos mais pobres e $11 \%$ dos mais ricos (Modelística, 2005). Já no Rio de Janeiro, ainda se observa um predomínio das mulheres nas caminhadas para trabalho e escola (Scovino, 2008), restringindo o seu alcance de acesso e a sua mobilidade, o que significa uma forma de exclusão.

Outros autores têm estudado, com muito mais detalhes, as características das cidades de países em desenvolvimento, como os da América Latina. Dentre eles, podem ser mencionados Kenworthy (2005), Vasconcellos (2000) e Flórez (1998), que confirmaram algumas das condições citadas anteriormente e acrescentaram outras, como as listadas a seguir:

- Apesar da importância do transporte público nos deslocamentos e do predomínio dos ônibus nesse setor, poucas cidades conseguiram implementar medidas que priorizem sua circulação, fruto das pressões e do forte lobby dos proprietários de automóveis (Vasconcellos, 2000). Entretanto, o projeto Transmilênio em Bogotá mostrou que é possível implementar essas medidas (http://www.bogota-dc.com/trans/ transmil.htm), como também foi feito em Curitiba;

- A estrutura urbana apresenta um ambiente mais restrito à motorização das viagens pela sua maior densidade populacional e menor proporção de espaço alocado às vias e estacionamentos;

- Grandes diferenças no desempenho dos veículos, pelos distintos tipos que compõem a frota circulando pela vias, desde veículos tracionados pela força humana até carros esportes, passando por várias categorias de caminhões. Essa heterogeneidade reflete-se na fluidez e na segurança do tráfego. Acrescenta-se a isso uma frágil disciplina na condução veicular e certa propensão à não observância da regulamentação, apesar de casos bem sucedidos, como o de Brasília, quanto ao respeito e prioridade aos pedestres e às suas travessias.

Como consequência dessas condições, normalmente se observam: número excessivo de veículos concentrados em corredores sem capacidade para atendê-los, conflitos e acidentes de trânsito, congestionamentos, desperdício de combustível, impactos no ambiente e degradação da qualidade de vida. Várias pesquisas tratam dos altos custos associados a esse modelo. Estudo 
da Prefeitura de São Paulo (PMSP, 2004) aponta que as regiões metropolitanas brasileiras perdem anualmente cerca de 30 bilhões de dólares nos seus congestionamentos. Ainda no Brasil, Borne (2003) cita que 55 milhões de brasileiros não têm acesso ao serviço de transporte público por não conseguirem arcar com o preço das tarifas, ou seja, aproximadamente um terço de sua população; que 30 mil mortes, 350 mil feridos, 120 mil deficientes físicos a cada ano, são responsáveis pelo comprometimento de $30 \%$ dos recursos do Sistema de Saúde a um custo de 2 bilhões de dólares por ano, sendo que $52 \%$ dos leitos hospitalares são por traumas cuja causa principal são os acidentes de trânsito.

Mesmo reconhecendo a heterogeneidade dos contextos e dos processos urbanos que se observam na América Latina, é bem provável que essas condições e externalidades se reproduzam em muitas metrópoles desse continente.

\section{OS PGVS E SUAS EXTERNALIDADES}

Como já mencionado, tanto a ocupação desordenada do solo - que reflete a desigualdade e a desordem prevalecentes - quanto à falta de integração dos transportes e de sua adoção como instrumento de promoção de mudanças e de desenvolvimento refletem as condições que caracterizam as metrópoles latino-americanas.

Flórez e Portugal (1996) afirmam que nas cidades latino-americanas é freqüente a ausência de um plano de ordenamento urbanístico que esteja devidamente respaldado em níveis técnico, político e social e que dê resposta aos interesses da comunidade em seu conjunto. A falta de leis e/ou de mecanismos de controle para fazer cumprir o plano - quando existe - é outro problema comum. Por outro lado, a ausência de um plano de infraestrutura e de transporte articulado com o ordenamento urbanístico, em um contexto amplo e de longo prazo, dificulta o aproveitamento dos recursos disponíveis, como a oferta viária e a sua utlização como ferramentas de desenvolvimento e redistribuição de renda. Os vícios das instituições, associados à baixa representatividade democrática, facilitam a violação das normas urbanísticas, com o conseqüente aumento de densidades e usos incompatíveis.

De acordo com Seguí e Petrus (1991), as redes de transportes nos países em desenvolvimento têm níveis de acessibilidades baixos e desiguais, restringindo a integração do território. Ao contrário, as redes dos países industrializados tendem a dispor de coesão interna, especialização e hierarquização, fornecendo padrões de acessibilidade mais eqüitativos. Talvez, por isto, fruto desse desequilíbrio de oferta de acessibilidade e da sua escassez em muitas localidades, o efeito da mudança de acessibilidade derivada de interven- ções na infraestrutura viária e de transportes seja mais visível na ocupação do solo e no desenvolvimento regional e local, conforme sugerem Hall e Banister (1995), Gakenheimer (1999) e Flórez (1998).

Gakenheimer (1999) ainda afirma que, apesar do planejamento do uso do solo como instrumento no gerenciamento da mobilidade (Travel Demand Management - TDM ou Mobility Management - MM) apresentar uma história mais direcionada aos países de maior renda, há um forte potencial de aplicação nos países em desenvolvimento. As altas densidades e uso misto do solo, o peso dos deslocamentos a pé e por transporte público verificados nas metrópoles latinoamericanas são condições favoráveis ao TDM, podendo este ser implementado pelo planejamento e controle do uso do solo. O crescimento acelerado de urbanização permite orientar esse desenvolvimento para promover as mudanças requeridas, principalmente quando de forma articulada às infraestruturas de transportes.

Nesse processo de interação entre transporte e uso do solo, destacam-se os empreendimentos de grande porte, aqui denominados como Pólos Geradores de Viagens (PGVs). Estes são locais ou instalações de distintas naturezas que têm em comum o desenvolvimento de atividades em um porte e escala capazes de exercer grande atratividade sobre a população, produzir um contingente significativo de viagens, necessitar de grandes espaços para estacionamento, carga e descarga e embarque e desembarque, promovendo, conseqüentemente, potenciais impactos. Os shopping centers, hipermercados, hospitais, universidades, estádios, terminais de carga, estações de transportes público e mesmo áreas protegidas do tráfego de passagem com múltiplas instalações produtoras de viagens são alguns tipos de PGV (Portugal e Goldner, 2003).

Os PGVs, portanto, são também concentradores de atividades no espaço e se caracterizam por impactar a acessibilidade e o desempenho dos sistemas de transportes e viário, como também por promover mudanças no uso do solo e no desenvolvimento urbano. Em função dessas suas potencialidades em gerar externalidades, é fundamental que os PGVs sejam planejados, localizados e dimensionados com vistas a se maximizar os efeitos positivos e minimizar os negativos. Esses impactos e respectivas modelagens de previsão relacionam-se não só às características locais, ao tipo e ao porte do PGV, mas também à natureza dos fluxos (passageiros e carga) - e aos modos de transporte envolvidos, que reforçam a complexidade desse tema.

Na América Latina, a usual falta ou não aplicação e respeito aos Planos Diretores e de Transportes, já comentada, restringe a disponibilidade de uma referência de desenvolvimento para toda a metrópole que determina as regiões que possuem infraestrutura de trans- 
portes com capacidade suficiente para atender às demandas de viagens geradas pelos PGVs e os tipos de PGVs que são compatíveis com as vocações e necessidades de cada local. Acrescenta-se a isso a ausência de redes viárias hierarquizadas que também poderiam servir de critério adicional para a localização e a escolha dos PGVs mais apropriados.

Por outro lado, mesmo com legislações nacionais e estaduais indicando a necessidade de realização de Estudos de Impactos quando da implantação ou ampliação de PGVs, não há, muitas vezes, regulamentação no âmbito local. Esse é o caso, por exemplo, do Brasil. Desde os anos 70, há uma legislação, consolidada nas décadas seguintes (Gusmão, 2001) que exige a realização de Estudos de Impactos Ambientais, cabendo aos municípios a responsabilidade de detalhar os procedimentos técnicos e administrativos necessários à implementação desse importante dispositivo. O Departamento Nacional de Trânsito (DENATRAN, 2001) comenta que, apesar dessas resoluções não tratarem especificamente de PGVs, na medida em que consideram os empreendimentos de impacto ambiental em geral, possuem dispositivos que dizem respeito a esses Pólos. Outra lei, de 2001, denominada Estatuto da Cidade, busca democratizar o uso do espaço urbano brasileiro, definindo instrumentos de gestão para as prefeituras poderem intervir com as ferramentas adequadas para articular as políticas urbanas a partir do Plano Diretor (Guilarte, 2006). O Estatuto da Cidade contribui na mediação de conflitos entre agentes, assim como na definição das responsabilidades municipais, inclusive sobre a realização de Estudos de Impactos de Vizinhança (EIV).

Por outro lado, tal Estatuto estabelece que uma lei municipal definirá os empreendimentos e atividades privadas e públicas em área urbana que dependerão de elaboração do EIV para obter as licenças de autorizações de construção, ampliação ou funcionamento a cargo do Poder Público Municipal. O EIV deverá ser executado de forma a contemplar os efeitos positivos e negativos do empreendimento ou atividade quanto à qualidade de vida da população residente na área e suas proximidades.

Apesar de quase uma década ter se passado após a lei ter sido sancionada, poucos municípios, como São Paulo, fizeram a sua parte no que diz respeito à regulamentação e à sistematização de um processo de licenciamento de PGVs e de uma metodologia para a realização de Estudos de Impactos. Apesar do Código de Trânsito Brasileiro, de 1998, ter consolidado a competência de gestão do trânsito urbano para os municípios sob a responsabilidade das prefeituras, a falta de incentivos técnicos e financeiros para a estruturação das administrações municipais resultou na implemetação dos órgãos de trânsito em menos de $10 \%$ dos municípios brasileiros (Borne, 2003).

Nesse contexto, usualmente o prefeito é quem arbitra os empreendimentos, cujos projetos serão submetidos a uma avaliação de impactos, geralmente quando a comunidade se mobiliza e exerce pressão para que isso ocorra. Quando tais Estudos são realizados, normalmente se dão por equipes técnicas insuficientes e que seguem metodologias, parâmetros e taxas de geração de viagens recomendadas por países desenvolvidos, principalmente pelo Institute of Transportation Engineers dos Estados Unidos (ITE, 2004, 2008).

As naturais críticas que ocorrem na modelagem e em específico às taxas propostas pelo ITE, como as feitas por Shoup (2003), se agravam pelas diferenças que envolvem a realidade das cidades dos EUA e das latino-americanas.

Com relação aos aspectos metodológicos, como a significância estatística e a seleção das amostras em áreas suburbanas com maior predomínio do uso de automóvel, vale mencionar o excesso de vagas de estacionamento que as taxas propõem para distintos usos de solo, no contexto das cidades dos EUA, incentivando o uso dessa modalidade de transporte individual.

As cidades latino-americanas, no geral, quando comparadas aos Estados Unidos da América, tendem a apresentar:

- Uma distinta divisão modal com uma elevada proporção de viagens não motorizadas e por transporte público, não por automóveis (Scovino, 2008);

- Em muitas cidades da América Latina tem aumentado de forma significativa o uso das motocicletas como modo de transporte particular (às vezes carregando mais de duas pessoas ou grandes volumes de mercadoria) e também como "moto-taxi” (Lopes, 2005; Santos, 2009);

- Sistemas informais de transportes que se mostram menos previsíveis;

- Uma heterogeneidade no território, que se expressa por diferentes padrões de viagens na mesma metrópole. De acordo com Portugal e Goldner (2003), é bem provável que um shopping center localizado em áreas centrais com boa oferta de transporte público e próximo de núcleos residenciais atraia não mais que $30 \%$ das viagens por automóveis. Já quando localizado em áreas mais periféricas, com menor densidade e disponibilidade de transporte público, o shopping center pode atrair mais de $80 \%$ dos deslocamentos por automóveis.

As taxas do ITE tendem a não corresponder à realidade observada em cidades da América Latina e suas estimativas devem superestimar as necessidades de espaço para os automóveis. Para se ter uma ordem de 
grandeza dessa incompatibilidade, segundo Andrade (2005), as estimativas do ITE tipicamente superam em cerca de $100 \%$ a tendência média das previsões feitas por modelos desenvolvidos no Brasil e na Venezuela para os shopping centers de até $75.000 \mathrm{~m}^{2}$ de área bruta locável (ABL), principalmente para os com menos de $55.000 \mathrm{~m}^{2}$ de ABL.

Além disso, verificam-se deficiências nos sistemas de informações quanto à infraestrutura viária e aos serviços de transportes (em termos de fluxos, cadastro viário, linhas de ônibus e passageiros), dificultando a realização de análises de capacidade e de desempenho viário. Existem limitações em algumas municipalidades quanto ao uso de ferramentas computacionais mais sofisticadas e há resistências por parte dos administradores de empreendimentos a disponibilizarem informações sobre as demandas de viagens e por vagas de estacionamento, dificultando o desenvolvimento de modelos apropriados.

Algumas instituições públicas, especialmente as universidades, vêm desenvolvendo pesquisas nesse campo de conhecimento, mas com seus resultados e propostas subutilizados e subvalorizados. Normalmente esses esforços ocorrem isoladamente e sem a existência de objetivos comuns. Uma Rede poderia gerar sinergias e uma base para potencializar mudanças no âmbito do transporte na América Latina, conforme tratado nos itens subseqüientes.

Nesse contexto, a complexidade que caracteriza as cidades da América Latina e os seus PGVs representa um desafio que pressupõe um processo de planejamento e controle mais elaborado e competente, sustentado técnica, política e socialmente.

\section{BASES PARA AS MUDANÇAS}

Vários estudos vêm sendo feitos para reverter a atual situação em que se encontra a América Latina e suas cidades, como o do Banco Mundial (2003), que revela os prejuízos no seu desenvolvimento, recomendando a adoção de reformas nos campos sociais e econômicos e de suas instituições; a melhoria de acesso dos pobres a bens e serviços vitais - especialmente educação e saúde - e a implementação de políticas de transferências de renda e inclusão social. A infraestrutura de transportes e a sua interação com o uso do solo no geral e particularmente com os PGVs são instrumentos importantes nesse processo de mudança (Ministério das Cidades, 2005; Portugal e Goldner, 2003), mesmo reconhecendo os múltiplos fatores nele envolvidos (Wong, 2001).

O Fórum Universal das Culturas, realizado em Barcelona em 2004, baseou a sua proposta de transformação em seis eixos relacionados à diversidade e sustentabilidade: diálogo; criatividade; intercâmbio; coope- ração e solidariedade entre organizações; e boas práticas (Wong, 2001). Os princípios da Política Nacional da Mobilidade Urbana Sustentável, no caso do Brasil, convergem para os princípios democráticos de liberdade, igualdade e fraternidade que embasam a democracia moderna, e ao mesmo tempo respondem aos três macro-objetivos acima indicados: desenvolvimento urbano integrado, sustentabilidade ambiental e inclusão social (Guilarte, 2006). Há também os conceitos usados no gerenciamento de mobilidade, cujos princípios estão relacionados à informação, à conscientização, ao conhecimento, à integração, à participação, à transparência e à parceria (Guilarte, 2006; Baud et al., 2001). Eles são fundamentais particularmente em contextos complexos com escassez de recursos e desigualdades.

Muitos desses valores e atributos estão intimamente vinculados ao planejamento, ao conhecimento e aos marcos institucional e legal.

O planejamento, ao antecipar os problemas futuros, evita que eles ocorram e estimula o exercício de cidadania ao tratar de recursos e projetos coletivos. Além de educativo, ao ressaltar a escassez de recursos e a busca pela negociação de conflitos, incentiva o respeito às diferenças e à atitude de solidariedade e partilha, na medida em que explicita a necessidade de ações cooperativas e conjuntas para enfrentar problemas de grande magnitude, incompatível com o enfrentamento individual. Ao contar com o respaldo técnico e social, serve de referência para aglutinar as forças políticas no entorno dele e reforça o sentido de se confiar no próximo na realização de trabalhos conjuntos.

O conhecimento resultante de um processo educacional - que envolve o ensinar e o aprender com uma atitude de mudança e criação - possibilita não só a transformação do conhecimento e da consciência, como também do próprio ambiente. Esse conhecimento pode ter diferentes veículos de expressão, como as bases científicas, práticas e experiências profissionais, sistema de informação, campanhas e participação da população, ensino e formação de pessoal. O conhecimento estabelece o grau de autonomia individual, bem como o de responsabilidade coletiva, motivações que conduzem a mudanças para um mundo melhor (http://www.egs.edu/resources/hannaharendt.html).

Os marcos institucional e legal - por interferirem nos níveis de articulação das políticas e de compatibilidade entre os recursos (humanos, financeiros, tecnológicos, entre outros) com as missões das organizações intervenientes (Chiavenato, 1999) - são fundamentais para dar sustentação às ações resultantes do planejamento e fundamentadas pelo conhecimento, com vistas às transformações desejadas pela população.

Seguindo essa macrodiretriz, insere-se o setor de 
transportes por tratar de uma infraestrutura coletiva, que consome grandes somas de recursos públicos e tem uma enorme capacidade de impactar a qualidade de vida, dependendo do seu nível de articulação e integração com um projeto de desenvolvimento e de ocupação do solo, destacando aqui os PGVs pela sua natureza de também gerar externalidades.

Nesse contexto, as medidas relacionadas aos PGVs são:

- Quanto ao planejamento, a realização de Planos Diretores como processos efetivos e sintonizados com o interesse público e a melhoria da qualidade de vida. No Brasil, eles são obrigatórios para os municípios com mais de 20 mil habitantes. Isso indicava, em levantamento de outubro de 2006, a necessidade de cumprimento da exigência de elaboração de plano por mais de 2000 municípios. Por terem um papel estruturador do território e estabelecerem as diretrizes de ocupação do solo, devem servir de critério para a escolha do local e tipo de PGV que pode ser implementado e usado para promover o desenvolvimento sustentado. Devem servir também de referência para o planejamento de transportes e de sua infraestrutura de forma integrada, hierarquizada e com uma configuração que forneça padrões de acessibilidade de acordo com a proposta de desenvolvimento. E também devem definir as classes de via nas quais os PGVs podem ser construídos;

- Em relação ao suporte institucional, é necessário que sejam especificados os órgãos responsáveis pelo processo de licenciamento de PGVs e suas atribuições, os mesmos devem dispor de estrutura, recursos e equipes preparadas para desempenhar suas atividades para apreciar os pleitos de construção ou ampliação submetidos pelos empreendedores. Esse processo deve contar com o respaldo legal, no qual devem ser definidos objetivamente, e no âmbito de cada município, o tipo e o porte de equipamentos urbanos que se constituem em PGV. Também devem ser observadas as exigências de construção - como número mínimo de vagas de estacionamento e a configuração geométrica dos acessos - no projeto de cada tipo de PGV;

- No que diz respeito ao conhecimento, é fundamental que o processo de licitação seja sistematizado e concebido segundo um ambiente de transparência e de estímulo à participação qualificada dos distintos atores envolvidos, como os empreendedores, a administração pública e a comunidade. Deve ser elaborado e fornecido um guia, contendo as etapas, os critérios e as técnicas a serem empregadas na realização do
Estudo de Impactos. Universidades e entidades comprometidas com a geração e a disponibilização de conhecimento atual e compatível com a realidade local devem ainda ser valorizadas e apoiadas em termos de desenvolvimento de taxas de geração de viagens, modelos, métodos, procedimentos e ferramentas de análise, cursos e sistemas de informação.

\section{A REDE DE PESQUISA: SUA RELEVÂNCIA E CONCEPÇÃO}

A Rede de Pesquisa, ao promover a integração e interação de vários grupos de pesquisa, explicita a importância do trabalho coletivo, reforça o respeito às diferenças, fortalece o exercício de parcerias e de articulação entre competências complementares em direção a objetivos comuns. Potencializa a aquisição e geração de conhecimentos individuais que são disponibilizados e distribuídos, buscando construir juntos um saber comum, com liberdade de criação (Baud et al., 2001; Chiavenato, 1999; Lévy, 2000). Ela reúne, então, valores fundamentais para a implantação das bases de transformação definidas anteriormente. De acordo com Matsuura (2005) e Fachinelli et al. (2001), o conhecimento possui duas qualidades notáveis: a não rivalidade e, uma vez prescrito o período de proteção sob os direitos de propriedade intelectual, a não exclusividade. Considera-se que há hoje uma consciência de que o desenvolvimento de sociedades baseadas no aprendizado e na partilha do conhecimento, como os trabalhos em redes, constitui a melhor maneira de promover um desenvolvimento humano sustentável, sendo a concentração de conhecimento em áreas geográficas restritas um dos principais obstáculos a essa proposta.

Há várias Redes bem sucedidas, atuando em distintas áreas de conhecimento e cumprindo com sua missão (Castells, 1998), inclusive em transportes (http://www.eu-portal.net). A mesma tendência se verifica na América Latina, o que se destaca num mundo globalizado e que vem incentivando a formação de blocos de países (http://www.eclac.cl; Banco Mundial, 2003; UNESCO, 2003; http://www.ulac.com.ve/ index.php; http://www.ufsm.br/mila).

No caso dos transportes, são conhecidas algumas iniciativas, como a Rede RECOPE-FINEP (Nassi et al., 2001) e de projetos interinstitucionais denominados de Redes financiados pelo Ministério de Ciências e Tecnologia/CNPq (http://metro.det.ufc.br/redetrafego). Ainda tem-se a RESET - Rede de Estudos de Engenharia e Socioeconômicos de Transportes (http://www.reset.coppe.ufrj.br/). Todas restritas fundamentalmente a instituições de ensino e pesquisa no Brasil. Já no âmbito latino-americano, as Redes abor- 
dam áreas de atuação correlatas, como o Observatório das Metrópoles (http://web.observatoriodasmetropoles.net), mas não especificamente em transportes e menos ainda em PGVs.

A área de transportes e sua interação com o uso do solo, em que a transferência de tecnologia e práticas não deve ser direta e passa por ajustes e adaptações às especificidades locais, precisa consolidar um conhecimento que atenda às necessidades particulares dos países da América Latina que, como já citado, apresentam muitas similaridades. Entretanto, um destaque relativamente pequeno é dado às experiências bem sucedidas que ocorrem nos países desse continente, bem como a sua produção científica. Sabe-se o que é feito nas universidades dos EUA e da Europa, mas muito pouco (se algo) nas universidades dos países vizinhos.

Ressalta-se que nos países da América Latina já há uma massa crítica de conhecimento gerada nas Universidades, Consultoras, Empresas e Entidades Públicas que desenvolvem pesquisas e trabalhos em transportes, PGVs e áreas correlatas. Isso se reflete no fluxo constante de congressos organizados regularmente na região, muitos dos quais remontam há mais de vinte anos, como CLATPU e PANAM, além dos nacionais (ANPET e ANTP, no caso do Brasil, e da Sociedade de Engenharia de Transporte, no Chile, por exemplo). Estima-se que esses eventos científicos consigam atrair anualmente mais que 3.000 participantes com a apresentação de cerca de 500 artigos e pôsteres.

Desde o início dos anos 1980, diversas pesquisas foram desenvolvidas sobre o tema de PGVs, particularmente por suas Universidades, com destaque para os shopping centers, para os quais recentemente foram desenvolvidos 8 modelos de geração de viagens de automóveis na América Latina (Andrade, 2005). Essas pesquisas recentemente contemplaram outros PGVs (especialmente Supermercados, Estabelecimentos de Ensino, terminais de carga e estações de transportes, bem como instalações residenciais e recreacionais) e suas dimensões de investigação (incluindo modelos de previsão de viagens de caminhões e procedimentos para avaliação de impactos ambientais e desenvolvimento socioeconômico). Isso se expressa por dezenas de teses, dissertações e livros, bem como centenas de artigos científicos produzidos na América Latina.

Embora se verifique uma consciência quanto à importância da interação entre os grupos de pesquisa, a falta de recursos tem restringido as iniciativas nessa direção. Hoje, as tecnologias de telecomunicações, com seus sucessivos progressos, favorecem e viabilizam a interação, integração e acesso ao conhecimento entre os muitos diferentes grupos de pesquisa na América Latina, sem perder de vista e aberta ao restante da comunidade internacional.

Nesse contexto, desenvolve-se a Rede Ibero- americana de Estudo em Pólos Geradores de Viagens, com a pretensão de integrar os grupos de pesquisa de universidades da América Latina, mais Portugal e Espanha, pelas identidades culturais, e simbolizar o compromisso com outros continentes. Assim como, sistematizar o conhecimento sobre os PGVs, os transportes, suas interações e seu contexto de pesquisa, como também propor procedimentos, modelos e parâmetros para análise dos impactos que os mesmos produzem no sistema viário, condizentes com a realidade.

Ao longo desse processo, intencionam-se a publicação de livros, artigos científicos, relatórios, manuais e guias de orientação; produção de teses de mestrado e doutorado; fornecimento de cursos para as prefeituras e os técnicos em geral, promoção e participação em eventos técnico-científicos; desenvolvimento de diretrizes, modelos e taxas de geração de viagens; criação de uma base de informações e a construção de um Portal disponibilizado na $w w w$ (do inglês World Wide $W e b$, rede mundial de computadores). Quanto ao Portal (http://redpgv.coppe.ufrj.br), este pretende atender à necessidade de se dispor de um fórum permanente de discussão e de socialização do conhecimento gerado pela Rede, como ferramenta, contribuindo para:

- Desenvolvimento e aprimoramento de pesquisas nas universidades;

- Melhor preparação das prefeituras para que possam assumir suas atribuições, planejar e controlar a construção e a ampliação de PGVs;

- Disponibilização de procedimentos e parâmetros mais atuais para técnicos e consultores para realização melhor sustentada dos Planos Diretores e dos Estudos e Relatórios de Impactos Ambientais e de Vizinhança;

- Melhor escolha dos locais e realização dos projetos pelos empreendedores;

- Defesa dos direitos das comunidades e, quando necessário, a exigência de estudos de impactos de vizinhança permitindo que a mesma exerça sua cidadania.

Espera-se que essa base de conhecimento possa ser de utilidade e aperfeiçoe o planejamento, dimensionamento e localização de PGVs e fortaleça a integração entre transporte-uso do solo-desenvolvimento, bem como contribua para as transformações desejadas e a melhora da qualidade de vida da população. E que colabore para reforçar a formação democrática e plural da população estimulando a sua participação e defesa de seus interesses de maneira mais efetiva nos processos de planejamento e gerenciamento urbano e de transportes.

Os primeiros contactos para a formação da Rede ocorreram no final de 2004, envolvendo pesquisadores de 9 universidades de 6 países sul-americanas (4 
brasileiras). Essa iniciativa foi ampliada e confirmada em reunião realizada no Rio de Janeiro em abril de 2005, com a presença de representantes de 16 universidades de 9 países (7 do Brasil, 6 da América do Sul e 3 da Península Ibérica). E contou com a aprovação e recursos do CNPq - Conselho Nacional de Pesquisa (Edital 016/2004 - PROSUL).

Atualmente a Rede é constituída por 30 universidades de 9 países: Argentina (Universidad Nacional de Córdoba e de Buenos Aires); Brasil (Universidade Federal do Rio de Janeiro, Amazonas, Bahia, Brasília, Ceará, Goiás, Juiz de Fora, Minas Gerais, Pernambuco, Rio Grande do Sul, Santa Catarina, São Carlos, Uberlândia, Instituto Militar de Engenharia, Universidade Estadual da Bahia, de Campinas e a Universidade de São Paulo - São Carlos); Colômbia (Universidad del Valle); Equador (Escuela Politécnica Nacional), Espanha (Universidad Politécnica de Cataluña, Universidad Complutense de Madrid); Peru (Universidad Nacional Mayor de San Marcos); Portugal (Universidade de Coimbra, do Minho e Técnica de Lisboa); Uruguai (Universidad de la República) e Venezuela (Universidad Simón Bolívar). Entre membros da equipe de trabalho e profissionais cadastrados na Rede, já são mais de 200 professores e pesquisadores que participam desse projeto coletivo.

A interação entre os membros da Rede e destes com a comunidade científica e o público em geral tem em seu Portal uma ferramenta fundamental. O Portal foi implantado e aberto ao público numa versão preliminar em junho de 2005, quando nos dois primeiros meses foi constatada uma média mensal inferior a 2.700 visitas (ou páginas consultadas), que passou a 8.000 nos 7 meses de 2005. Em 2006, essa média foi para 15.000, alcançando quase 17.000 em 2007 e ultrapassando 25.000 em 2010. Entretanto, a sua manutenção e aprimoramento exigem recursos, o que encoraja novas parcerias e a busca de novas fontes de financiamento. Nesse sentido, a Rede - através de seus pesquisadores - vem desenvolvendo e submetendo propostas aos órgãos de fomento, destacando os editais PROSUL (CNPq) - que se destina a garantir principalmente a mobilidade da equipe de Universidades da América do Sul - e o PRONEX (CNPq-Faperj). Quanto a este, por ser orientado a núcleos denominados como de excelência, destaca-se que a aprovação do Projeto da Rede tornou possível credenciar esse seleto grupo, talvez de forma pioneira no Brasil no setor de transportes.

Com base nos registros feitos e disponibilizados pelo site da Rede nos módulos "Produção Intelectual" e "Bibliografias", bem como por informações fornecidas pelos membros da equipe, foram contabilizadas as publicações relacionadas à temática desse Projeto para os cinco anos que antecedem a sua implantação (de
2000 a 2004), bem como aquelas produzidas pelos membros dessa equipe a partir de 2005 (quando a Rede começou a ser concebida) até 2009 (cinco anos subseqüentes). No que diz respeito aos artigos científicos publicados em periódicos e anais de congressos nacionais e internacionais, observa-se que após a formação da Rede, a média anual de publicações associadas ao objeto de pesquisa passou de 8,4 para 53,8, representando um aumento equivalente a $540 \%$. Prevê-se para 2010 uma produção superior a 60 artigos científicos, confirmando esse crescimento.

Em relação à formação de pessoal, considerando as mesmas fontes e o recorte temporal usados anteriormente, verifica-se que após a formação da Rede a média anual de orientações concluídas (teses e dissertações) passou de 7,6 para 14,0, o que equivale a um aumento de $84 \%$. No que diz respeito às teses de doutorado, esse incremento foi de cerca de $400 \%$.

Esses quantitativos revelam o esforço bem sucedido na geração de trabalhos científicos e na formação de recursos humanos que se ampliam e se multiplicam pelas sinergias e oportunidades de interação proporcionadas pela Rede.

\section{CONCLUSÕES E RECOMENDAÇÕES}

Com base numa ampla revisão bibliográfica, verificou-se que as condições existentes na América Latina, pela sua gravidade, indicam a necessidade de mudanças. Por outro lado, que elas são possíveis, fruto de algumas experiências bem sucedidas observadas nesse continente. Para tanto, é preciso investir em um ambiente que valorize o conhecimento e a participação da população, em um processo sintonizado com o interesse público. Ou seja, que o poder, predominantemente restrito a alguns grupos mais influentes, possa de forma respaldada técnica, política, institucional e legalmente - ser dividido e compartilhado com a população na busca da concretização de seus sonhos, em um exercício permanente de cidadania e responsabilidade social.

Os megaempreendimentos exigem investimentos importantes em infraestruturas de transportes, que devem ser parte de um plano integrado de desenvolvimento e articulados ao uso do solo. Na literatura disponível, vários autores também explicitam as potencialidades dos transportes e dos PGVs para serem usados, na América Latina, como ferramentas capazes de estimular maior eqüidade e melhor qualidade de vida. Assim, o melhor conhecimento das relações entre atividades socioeconômicas e a mobilidade é essencial para o planejamento dos PGVs. O contexto latinoamericano mostra fortes variações, mas apresenta algumas características comuns que deverão permitir sinergias de pesquisa nesse processo de análise. 
Destaca-se ainda a produção científica e a formação de recursos humanos, reunidas em teses, dissertações, monografias e artigos científicos, cuja série histórica mostra que, após a implementação da Rede, os indicadores de desempenho experimentaram um salto significativo em termos de quantidade de trabalhos. Também vem se fortalecendo a interação entre os grupos de pesquisa. Além de a mesma ocorrer cotidianamente pelo Portal e sistematicamente pelas atividades associadas às reuniões dos membros da Rede, a convênios e à participação em bancas comuns. Ultimamente vem aumentando o número de publicações, envolvendo pesquisadores de distintas universidades e países.

A Rede de Pesquisa aparece como uma efetiva maneira para partilhar experiências individuais derivadas de casos observados na América Latina, potencializando a aquisição e a geração de conhecimentos que são disponibilizados e distribuídos e buscando construir simultanemamente um saber comum, com liberdade de criação e autonomia individual. Ao promover a integração e a interação de vários grupos de pesquisa, explicita a importância do trabalho coletivo, reforça o respeito às diferenças, fortalece o exercício de parcerias e de articulação entre competências complementares em direção a objetivos comuns. Esperase, portanto, que a Rede Ibero-americana de Estudo em Pólos Geradores de Viagens consiga cumprir com a sua missão de contribuir para a aceleração dos processos de planejamento integrado de transporte-uso do solo - PGV na América Latina, assim como fortalecer seus grupos de pesquisa, produzindo métodos e modelos mais compatíveis com a sua realidade em direção a um desenvolvimento sustentável em termos ambiental, social e econômico.

\section{AGRADECIMENTOS}

Licinio da Silva Portugal e Antônio Nélson Rodrigues da Silva agradecem ao $\mathrm{CNPq}$ pela bolsa de produtividade e ao CNPq-Faperj pelo apoio ao desenvolvimento da Rede Ibero-americana de Estudo em Pólos Geradores de Viagens.

Josefina Flórez agradece Universidad Simon Bolivar pelo seu apoio a essas atividades de pesquisa e ao CNPq-Faperj pelo apoio ao desenvolvimento da Rede Ibero-americana de Estudo em Pólos Geradores de Viagens.

\section{REFERÊNCIAS BIBLIOGRÁFICAS}

Andrade, E. P. (2005) Análise de Métodos de Estimativa de Produção de Viagens em Pólos Geradores de Tráfego. Dissertação de M.Sc. PET/COPPE/UFRJ, Rio de Janeiro, Brasil.

Banco Mundial (2003) Inequality in Latin America and the Caribbean: Breaking with History? Washington. Disponível em: <http://publications.worldbank.org/ecommerce/catalog/product?it em id=4604784>. Acesso em: 05 ago. 2010.

Baud, I.; S. Grafakos; M. Hordijk; J. Post (2001) Quality of Life and Alliances in Solid Waste Management - Contributions to Urban Sustainable Development. Cities 18 (1), 3-12

Borne, L. N. (2003) Plano Diretor, Transporte e Mobilidade Urbana. V Conferência das Cidades. Dezembro. Brasília, Brasil.

Boye, O. (2001) Los acuerdos regionales para la deuda externa en América Latina y el Caribe. Palestra do Secretário Permanente do SELA, na Cúpula sobre a Dívida Social, organizada pelo Parla- mento Latinoamericano. Caracas, julho de 2001. Disponível em: $<$ http://lanic.utexas.edu/ sela/AA2K1/ESP/ponen/ponen20.htm>. Acesso em: 15 jun. 2005.

Castells, M. (1998) La société em reseaux. Fayard, Paris, France.

CEPAL (2005a) América Latina y el Caribe: proyecciones 2005. Serie Estudios Estadísticos y Prospectivos. Comisión Económica para América Latina y el Caribe. No. 32. Abril 2005. Disponível em: <www.eclac.cl>. Acesso em: 30 jun. 2005.

CEPAL (2005b) A América latina e o caribe cumprirão algumas metas do milênio, porém a região está atrasada na luta contra a pobreza. Estudo das nações unidas sobre a região. Comisión Económica para América Latina y el Caribe. Disponível em: <www.pnud.org.br/arquivos/ODM_CEPAL_geral.doc>. Acesso em: 30 jul. 2010.

CEPAL (2009) Anuário Estatístico 2009. Comisión Económica para América Latina y el Caribe. Disponível em: $<$ http://websie.eclac.cl/anuario_estadistico/anuario_2009/esp/defa ult.asp>. Acesso em: 20 jul. 2010.

Chiavenato, I. (1999) Introdução à Teoria Geral da Administração. Ed. Compacta. Rio de Janeiro: Campus. Brasil.

DENATRAN (2001) Manual de Procedimentos para o Tratamento de Pólos Geradores de Tráfego. Departamento Nacional de Trânsito. Ministério das Cidades. Dezembro. Brasília, Brasil.

Fachinelli, A. C.; Marcon, C.; Moinet, N. (2001) A prática da gestão de redes: uma necessidade estratégica da Sociedade da Informação. Site "Sociedade da Informação: inclusão e exclusão". Disponível em: http://www.comciencia.br/ reportagens/socinfo/ info14.htm. Acesso em 11 de Novembro, 2005.

Flórez, J. e Portugal, L. S. (1996) Caracterización y Análisis de la Accesibilidad, Calidad Urbana y Condiciones Sociales del Vecindario en la Selección Residencial. El Caso Latinoamericano. VII Congreso Iberoamericano de Urbanismo, Pamplona. Espanha.

Flórez, J. (1998) Accesibilidad, Calidad Urbana y Groups Socioeconómicos en el Patrón de Localización Residencial. El Caso de Caracas. Tese de Doutorado Universidad Politécnica de Cataluña, Escuela de Ingenieros de Caminos, Canales y Puertos de Barcelona, Espanha.

Gakenheimer, R. (1999) Urban Mobility in the Developing World. Transportation Research Part A 33, 671 - 689.

Gomide, A. de Á. (2003) Transporte Urbano, Pobreza e Inclusão Social. In: Panorama Nacional da Pesquisa e Ensino em Transportes. Anais do XVII ANPET. Congresso de Pesquisa e Ensino em Transporte, v. 2, Rio de Janeiro, Brasil. p. 1082-1093.

Guilarte, M. A. (2006) Gerenciamento da mobilidade: uma contribuição metodológica para a definição de uma política integrada dos transportes no Brasil. Tese de D.Sc. PET-COPPE/UFRJ. Rio de Janeiro. Brasil.

Gusmão, A. C. (2001) Programa de Capacitação Ambiental - Controle de poluição ambiental. Curso do Instituto de Biologia da UFRJ. Rio de Janeiro. Brasil.

Habitat (1987) Centro de las Naciones Unidas para Asentamientos Humanos. Informe mundial sobre los asentamientos humanos. Edit. Ministerio de Obras Públicas y Urbanismo, Madrid.

Hall, P.Y. e D. Banister (1995) Summary and Conclusions. Charter 20. In: Transport and Urban Development. E\&FN Spon.

IBGE (2010) Instituto Brasileiro de Geografia e Estatística. Disponível em: <http://www.ibge.gov.br/censo/>. Acesso em: 7 jul. 2010

ITE (2004) Parking Generation. $3^{\mathrm{a}}$ Edição. Institute of Transportation Engineers. Washington D.C.

ITE (2008) Trip Generation. $8^{\text {a }}$ Edição. Institute of Transportation Engineers. Washington D.C

Kenworthy, J. (2005) Making urban transport more sustainable in developed and developing cities: some key perspectives and poliy implications from the millennium cities database for sustainable transport. I Curso Internacional de Transporte e Sustentabilidade. ANTP/Movimento,São Paulo, Brasil. p. 200-227.

Lévy, P. (2000) A Inteligência coletiva: por uma antropologia do ciberespaço. $3^{a}$ edição. São Paulo: Loyola. Brasil. 212 p.

Lopes, S.P. (2005) Elaboração de Modelos Matemáticos para Análise, Avaliação e Previsão da Motorização no Brasil. Tese de D.Sc. COPPE/UFRJ, Rio de Janeiro, Brasil.

Matsuura, K. (2005) Rumo às sociedades do conhecimento. Diretor-geral da Unesco (Organização das Nações Unidas para a Educação, a Ciência e a Cultura). Folha de São Paulo de 13 de novembro, 2005.

Ministério das Cidades (2005) Motivações que Regem o Novo Perfil de Deslocamento da População Urbana Brasileira. Pesquisa de I- 
magem e Opinião sobre os Transportes Urbanos no Brasil. Agosto. Brasil.

Modelística C.A. (2005) Planificación y Diseño de una Red Integrada de Transporte Público para el Área Metropolitana de Caracas: Informe: Fase I - Estudio de Movilidad. Alcaldía del Distrito Metropolitano de Caracas. Caracas.

Nassi, C.; A. Brasileiro; E. Kawamoto; L. A. Lindau (2001) Transportes: experiências em rede. Rio de Janeiro: FINEP, Brasil. 300 p.

Negrón, M. (2001) Ciudad y Modernidad. El Rol del Sistema de Ciudades en la Modernidad de Venezuela: 1936-2000. Ediciones del Instituto de Urbanismo, Universidad Central de Venezuela, Caracas.

Prescott, J. (2005) Our Towns and Cities: The Future. Full Report. White Paper, Deputy Prime Minister. England. 183 p. Disponível em: <www.odpm.gov.uk>. Acesso em: 22 mar. 2005.

Piccini, M. (2003) Sobre a comunicação nas grandes cidades. Revista Opinião Pública, Campinas. Outubro, 9 (2), 01-19.

PNUD (2010) Informe Regional sobre Desarrollo Humano para América Latina y el Caribe 2010: Actuar sobre el futuro: romper la transmisión intergeneracional de La desigualdad. $-1^{\text {a }}$. ed. - Programa de las Naciones Unidas para el Desarrollo. San José, Costa Rica. 208 p.

PMSP (2004) Os Custos do Deslocamento do Trabalho no Brasil, tomou por base informações da Pesquisa Nacional por Amostra de Domicílios (PNAD) do IBGE - Instituto Brasileiro de Geografia e Estatística. Maio. Prefeitura do Município de São Paulo. São Paulo, Brasil. 12 p. Disponível em: $<$ http://www.econ.fea.usp.br/nereus/eae503/os_custos_ do_deslocamento_do_trabalho_no_brasil.pdf $>$. Acesso em: 12 jun. 2007.

Portugal, L. S. e Goldner, L. G. (2003) Estudo de Pólos Geradores de Viagens e de seus Impactos nos Sistemas Viários e de Transportes. Edgard Blücher, São Paulo, Brasil.

Portugal, L. S. e Flórez, J. (2006) Latin American Transportation Research Network: A Tool for Transforming and Upgrading the Quality of Life. In: 85th Annual Meeting of the Transportation Research Board, CD-Rom. Washington D.C.

Prazeres, L. M. (1998) A interface social seus desafios para gestores de política ambiental nas cidad. In: Encuentro Internacional de la Ciudad de México. Sobre Participación Social en la Gestión del Medio Ambiente Urbano. México City, 16 al 18 de noviembre de 1998. Disponível em: <http://web.idrc.ca/es/ev-23745-201-1DO_TOPIC.html>. Acesso em: 15 ago. 2010.

Santos, J. D. A. (2009) Procedimento para Definir Trechos em Via Pública para Estacionamento de Motocicletas em Centros Urbanos. Dissertação de M.Sc. Programa de Engenharia de Transportes. COPPE/UFRJ. Rio de Janeiro, Brasil.

Scovino, A. S. (2008) As viagens a pé na cidade do Rio de Janeiro: Um estudo da mobilidade e exclusão social. Dissertação de M.Sc. Programa de Engenharia de Transportes. COPPE/UFRJ. Rio de Janeiro, Brasil.

SELA (2003) Sonja Welch, Etapa Ministerial de la XXIX Reunión del Consejo Latinoamericano. 25 de noviembre. Sistema Económico Latino Americano. Caracas, Venezuela. Disponível em: $<$ http://www.sela.org/public_html/AA2K3/ESP/ disc/discurso18.htm>. Acesso em: 9 jun. 2006.

Seguí, J. Y. e Petrus, J. (1991) Geografía de las Redes de Transporte. Espacio y Sociedad, Ediciones Síntesis, Madrid, Espanha.

Shoup, D. (2003) Truth in Transportation Planning. Journal of Transportation and Statistics. Vol 6 No 1. p. $1-12$

SNH (2009) Déficit habitacional no Brasil 2007. Secretaria Nacional de Habitação. Ministério das Cidades,. ISBN: 978-85-60133-93-2. Brasília, 129p.

UNESCO (2003) Políticas culturais para o desenvolvimento: uma base de dados para a cultura. Brasília, Brasil, $236 \mathrm{p}$.

Vasconcellos, E. A. (2000) Transporte Urbano nos Países em Desenvolvimento. Reflexões e Propostas. $3^{\mathrm{a}}$ Ed. Unidas. São Paulo-Brasil.

Wong, C. (2001) The Relationship Between Quality of Life and Local Economic Development: An Empirical Study of Local Authority Areas in England. Cities 18 (1), 25-32.

Sites:

http://www.denatran.gov.br/frota.htm. Acesso em: 25 ago. 2010.

http://europa.eu.int/comm/europeaid/projects/urbal/infos/urb11pt.pdf. A-

cesso em: 3 jan. 2008.

http://metro.det.ufc.br/redetrafego. Acesso em: 13 maio 2010.

http://www.bogota-dc.com/trans/transmil.htm. Acesso em: 21 abr. 2009.

http://www.egs.edu/resources/hannaharendt.html. Acesso em: 12 jul. 2007.

http://www.eu-portal.net. Acesso em: 11 nov. 2008. http://www.iesalc.unesco.org.ve. IESALC - Instituto Internacional para o Ensino Superior para América Latina e no Caribe. Acesso em: 2 out. 2009. http://www.reset.coppe.ufrj.br/

http://web.observatoriodasmetropoles.net/. Acesso em: 17 jul. 2010.

http://www.oas.org. OEA - Organização dos Estados Americanos. Acesso em: 25 jun. 2009.

http://www.ulac.com.ve/index.php. ULAC - Universidade LatinoAmericana e do Caribe. Acesso em: 2 out. 2009.

http://www.ufsm.br/mila. MILA - Mestrado em Integração LatinoAmericana. Acesso em: 23 jul.2010. 